\title{
Judging Mental Health Disorders Using Decision Tree Models
}

\author{
Sandip Roy ${ }^{1}$, Aithal P. S. ${ }^{2}$, \& Rajesh Bose ${ }^{3}$ \\ ${ }^{1}$ Post-Doctoral Research Fellow, Srinivas University, Mangalore 575 001, India \\ Orcid ID: 0000-0002-5447-803X; E-mail: sandiproy86@gmail.com \\ ${ }^{2}$ College of Management \& Commerce, Srinivas University, Mangalore, India, \\ Orcid ID: 0000-0002-4691-8736; E-mail: psaithal@,gmail.com \\ ${ }^{3}$ Associate Professor, Brainware University, Kolkata, West Bengal 700125, India \\ Orcid ID: 0000-0002-0967-455X; E-mail: bose.raj00028@gmail.com
}

Area/Section: Health Sciences.

Type of the Paper: Research Paper.

Type of Review: Peer Reviewed as per $|\mathrm{C}| \mathrm{O}|\mathrm{P}| \mathrm{E} \mid$ guidance.

Indexed in: OpenAIRE.

DOI: $\mathrm{http}: / /$ doi.org/10.5281/zenodo.4588415.

Google Scholar Citation: IJHSP.

\section{How to Cite this Paper:}

Roy, Sandip, Aithal, P. S. \& Bose, Rajesh, (2021). Judging Mental Health Disorders Using Decision Tree Models. International Journal of Health Sciences and Pharmacy (IJHSP), 5(1), 11-22. DOI: http://doi.org/10.5281/zenodo.4588415.

International Journal of Health Sciences and Pharmacy (IJHSP)

A Refereed International Journal of Srinivas University, India.

(C) With Author.

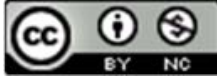

This work is licensed under a Creative Commons Attribution-Non-Commercial 4.0 International License subject to proper citation to the publication source of the work.

Disclaimer: The scholarly papers as reviewed and published by the Srinivas Publications (S.P.), India are the views and opinions of their respective authors and are not the views or opinions of the SP. The SP disclaims of any harm or loss caused due to the published content to any party. 


\title{
Judging Mental Health Disorders Using Decision Tree Models
}

\author{
Sandip Roy ${ }^{1}$, P. S. Aithal ${ }^{2}$, \& Rajesh Bose ${ }^{3}$ \\ ${ }^{1}$ Post-Doctoral Research Fellow, Srinivas University, Mangalore 575 001, India \\ Orcid ID: 0000-0002-5447-803X; E-mail: sandiproy86@gmail.com \\ ${ }^{2}$ College of Management \& Commerce, Srinivas University, Mangalore, India, \\ Orcid ID: 0000-0002-4691-8736; E-mail: psaithal@gmail.com \\ ${ }^{3}$ Associate Professor, Brainware University, Kolkata, West Bengal 700125, India \\ Orcid ID: 0000-0002-0967-455X; E-mail: bose.raj00028@gmail.com
}

\begin{abstract}
This research presents a categorization replica to have the discernment of the result of distinct psychological health hazard which got improved with the implementation of the replica of decision tree. Among 3000 contestants approximately for different medical analysis, we get the instruction data regarding decision tree information from the answers of the queries. It is displayed by the exploratory outcomes that the suggested replica of the decision tree can find the significant framing of conclusion which influences Clinical discernment Precision. Such conclusions framing comprising in result such as recurrence or non-recurrence for clinical physical sickness, maturity, sex, duration of psychologically physical sickness, span for having drugs as well as suggested drugs that will be able to be applied as an instance of the assessment of the comprehensive precision of medical professionals.
\end{abstract}

Keywords: Depression Relapse, Decision Tree, Heath Data Analytics, Judgement Analysis, Medical diagnosis.

\section{INTRODUCTION :}

Our regular life demands from us to resolve different kinds of major solutions of different and significant event. If folks want to come to any conclusion of a particular event, folks are inclined to depend upon their own skill, understanding, maturity, experience, analytical competence etc. Besides, sometimes they depend on the advice of other adepts regarding an issue. Nevertheless, various adepts' solutions of a particular issue may vary. To make one easily understand about it, we can say that the various doctors' solutions of a particular health issue of a patient may vary on account of their personal discernments. Confusions created by worry are a customary psychological ailment in the USA. It has made psychological health hazards, to 40 million grownups in the USA, who are eighteen year old or older than that. If you gather recent yesteryears' statistics, you will find that every year $18.1 \%$ of the total number of people of the USA should be treated for the ailment created by worries. But just $36.9 \%$ of such patients get therapy for it [1]. If we accumulate further reports then we shall notice that the number of folks who are admitted in hospitals every year due to the ailments created by psychological issues, is six times more inclined than the number of folks not getting affected by the ailments created by worry, are three to five times more inclined to visit the physicians than to get admitted in hospitals [2]. If we keep an eye at the report of 2017, we can see that $197 \cdot 3$ million (95\% UI 178.4-216.4) citizens were affected by psychological ailments in India, counting $45 \cdot 7$ million $(42 \cdot 4-49 \cdot 8)$ in the midst of ailments created by dejection and 44.9 million (41.2-48.9) in the midst of ailments created by worry $[3,4]$. At present, dejection reveals a customary psychological illness that make above 264 million folks all over the globe $[5,6]$. When one is affected by it, the symptoms as follows, are visible in one: unrelenting melancholy, frustration and many more. One won't have any kind of satisfaction or happiness in mind. This will also lead the dejected patients to some customary symptoms [7] such as insomnia, loss of appetite, weariness and inattentiveness in one's concerned work. Now, we consider that dejection is an acute problem of the affliction $\mathrm{n}$ all over the globe. Besides, dejection gives a severe impact on the ailments which the whole world is utterly concerned about $[8,9]$. On account of dejection a man is severely affected even by health, which leads him to be unable to perform his own work in future, as mental illness tells upon one's physical health too [10]. If one is dejected, then it is seen that in one's lifespan, one is attacked with such syndrome 
with a number of times. [11, 12]. It is also observed that dejection engulfs many folks, making their life even at stake. Dejection shows different symptoms in different affected victims. It is seen that this turns out to be a persistent ailment for several patients. Along with that, this also shows a renewal habit for a great many folks. It is also observed that generally, a man who ha gets affected by dejection gets such hazards four to five times in his lifespan. A physician states that deterioration related to dejection is in reality of different event which is visible in the lifespan of less than six months, once a patient gets diagnosed with severe dejection. The reappearance shows sometimes a few novel attributes which appear almost after a semester or more than the first diagnosis is made. In spite of having the timeframe, this will able to be deflating for sensing dejection indications like melancholy, weariness, and bad temper, moving stealthily back into your life $[13,14]$. If there is the recurrence or setback of dejection, the treatment of it is able to be made in numerous methods. We can do it either via an amalgamation of treatments $[15,16]$ or doctor may refer to antidepressant treatment $[17,18]$ and psychological treatment $[19,20]$. Several studies have been initiated, and they have provided a number of dreary reports that have spotted the predictions of worsening of dejection of one affected by this. Those who have made research on it, have stated that dejection is a severely periodic ailment, and if one is affected by it once, it will generally be visible in one within 5 years of it. It is also stated that if we get an average rate of dejection visible in one, also get five to nine different dispiriting periods in his total lifespan [21]. There is much probability of a person affected by dejection once, of $50 \%$, to get into this trouble once more, even after diminution of the severity of this ailment. If the person gets affected by dejection twice, the hazard becomes $70 \%$ and if he gets affected by it thrice or more than that, then the hazard becomes almost 90\% [22]. If we keep an eye at Major depressive disorder (MDD), we shall discover that the reappearance of the indications is generally visible in the affected folks, every after two successive months and it occurs in the meantime of the different periods of time on which time benchmarks do not come across for a Major Depressive Episode (MDE). There is also a mandatory comeback of indications of minimum five among nine indications of dejection [23, 24]. Several victims affected by these kinds of considerable hazards of the reappearance afterwards, are with $60 \%$ lifespan the hazard of reappearance after the initial most important dismal events. Among this stat, we can see that seventy percent of them together with two MDE have reappearances of life, and ninety percent of these together with 3 or more than that have occurrence of additional periodic events [25]. Moreover, seventy five percent to half of the victims affected by such disease in a year of absence of therapy have a relapse of such disease [26]. Whenever any reappearance is observed, it conveys ten to twenty percent danger of turning out to be and consistent [27]. On the contrary, persistent MDD augments hazards of noteworthy useful harm, suicide and co morbid corporeal wellbeing hazards [28-30], sustaining serious physical condition and financial problems [31]. On account of it, researchers have been at rest incessantly going on with their exertion diverse features for exploring the elucidation in the deterioration to the victims who are dejected.

\section{BACKGROUND STUDY :}

Several online podiums are there which are able to offer us for saving information to keep an eye at the data related to a patient. To make presentation of the information of patients, several online podiums exist, which are able to save data [32]. Besides, this assists physicians to come to the conclusion of some objectives. At presents, various studies have been initiated, that secure the repetition of dejection [33'34]. On account of the non-appearance of physical signs or indications, it is more difficult to make detection and other medical states such as ache in chest, Measles and a few more. At present, doctors and other medical staff apply the PHQ-9 and PHQ-2 ingredients of the Patient Health Form to detect dejection [35-36]. At present, the majority of folks who suffer from psychological ailments of health declined for getting prompt admittance for sufficient concern. This research [37] allows the writers to discourse on US Hispanic/Latino folks distinctly marginalized in the concern related to psychological health and there were conventionally truly intricate people for the appointment in medical tests. Nevertheless, such people got growing admittance to cell phone mechanism, and in such case, more than $75 \%$ possess a smart phone. At present, such mechanisms get the competence for conquering familiar obstacles to have admittance and benefits of customary evaluation and methods of therapy [37]. This research [38] shows that psychological ailments are widespread to the folks with the range of sixteen to twenty-five years old. It is also observed that such diseases are able to disintegrate the growth of such patients forever. Simply obtainable mobile health (mHealth) application for cell phones received huge competence to ward off and receive advanced arbitrations of psychological ailments visible in youths or grown-ups. On the contrary, it was necessary for making arbitrations which are able to assist folks 
for the detection of high-potential mobile applications and making the implementation of them for the alteration of physique and attitude. When now the application of smart phone is found everywhere, and the application sector for smart phone applications is aimed at the incessant rise of psychological health, it is yet to be clear, why the discrete applications are applied for the therapy of psychological health signs [39]. Psychological ailments that are now a customary issue all over the globe, most of the time, are able to get a harmful influence on the life of such diseased folks. It is also observed that that these get inadequately treated till now [40]. In spite of subsistence of a vast arrangement of proof dependent on therapies, most of the folks having indications of psychological ailments refrain from any therapy irrespective of their financial conditions [41, 42]. Dejection most of the time commences in teenage years. So, we should discover the means to get rid of it in the teenage. In this research, the writers modified a method dependent on worldwide analytical behavioral treatment (MEMO CBT) that is conveyed through multimedia cell phone texts for teenagers [43]. It is observed that a growing keenness for getting the applications and a few more different user mechanisms in psychological concern of physique for a few years [44-46] of smart phones is visible. The following procedure is done for considering the detection of the psychological ailments of an affected person. They are asked an illustrated series of questions. Thus, it is measured, what is a time bounding and expensive procedure. The purpose of doing so, is to make an application of the machine learning prototype and assessment of discovering whether a speculative ability of patient data is there for augmenting the detection of the events related to dejection $[6,10,47,48]$. In this research, there is a target to create a podium which will be able to categorize the dataset into reappearance and non-reappearance. It should be noted that no reappearance on the basis of age, sex, drug and therapy time formerly and later of providing drugs to the patients. It is also speculated, which drug should be provided to the patient if the patient has a recurrence of such ailment even after the remission of it. On the basis of the recurrence issue, the suggested algorithm of this research, proposes to intake the drug on the basis of the assorted forms which are filled by the victim of such ailments while visiting hospitals.

\section{PROBLEM FORMULATION :}

The specimen of one hundred and nine folks approximately in the National Institute of Health Organization (named the Clinical body) allows us to process a group of 3000 data. This research that vastly gets Recurrence and Non Recurrence result together with the treatment arranged for the patient (Lithium, Imipramine or Placebo), has applied that. Such therapy was examined by us, comparing with other therapies, and in such cases, we concentrated on Time, AcuteT, Age and sex procedures that were expressed in the context of Questions - Answer. In the beginning customary statistical trials and machine learning algorithms are applied in the viable research [10]. This kind of data is able to be discovered inconspicuously and the algorithms suggested in this research defend confidentiality in view of that.

The dataset supplies the information as follows:

- Hospt: The hospital which victim was taken to, indicated by a numeral among 1, 2, 3, 5, or 6 for five hospitals.

- Treat: The treatment supplied to the victims (Lithium, Imipramine, or Placebo)

- Outcome: a reappearance occurred while being in the treatment or not (Recurrence/No Recurrence)

- Time: If there is reappearance then the time (days) till the happening of it, or if there is no appearance, then the victim's attachment length (days) in the research.

- AcuteT: The period (days) in which the victim got dejected before the study.

- Age: Patient's age in years, in the time of admittance of the research.

- Gender: Patient's sex, in case of a woman it's denoted by 1 and in case of a man, it is denoted by 2 . From the entire accumulated data, in this study, almost $33 \%$ data is implemented as training data. The remaining portion is implemented for a trial group. Since such a research has been made for the speculation of the drug on the basis of this research's suggested assortment of data, here the mean of the precision of man is classified into two Parts. When we find it equal or greater than " 0 ' 5 ", the result is calculated as " 1 ", and on the contrary, when it we find it less than " 0.5 ", the result is calculated as "0". It is root node that assists us to check the categorization. After that, we come down 
from the tree branch. The Above mathematical expressions show the method of training of a decision tree segment as follows [49] [50]:

Step 1: The redundancy is measured of training data group in accordance (1) with

$$
\text { Entropy }(S) \equiv-p_{+} \log 2 p_{+}-p_{-} \log 2 p_{-}
$$

where $p_{+}$is the proportion of positive examples in $\mathrm{S}$ and $p_{-}$is the proportion of negative examples in $S$.

Step 2: We use (2) to calculate the information gain of a testing decision variable (A).

$$
\text { Gain }(S, A) \equiv \text { Entropy } \quad(S)-\sum_{v \in \text { Values }} \frac{\left|S_{v}\right|}{\left({ }_{A}\right)} \text { Entropy } \quad\left(S_{v}\right)
$$

Where Values (A) is the set of all possible values for attribute $A$, and $S_{v}$ is the subset of $S$ for which attribute $A$ has value $v$.

Step 3: The largest value of reducing redundancy or the highest information profit of the conclusion inconsistent was opted to construct the tree prototype. This method is recurred for the sub tree at the novel node.

Diagram 1 and the suggested algorithm are those successively, in which the outcomes of redundancy and the utility of information are illustrated.

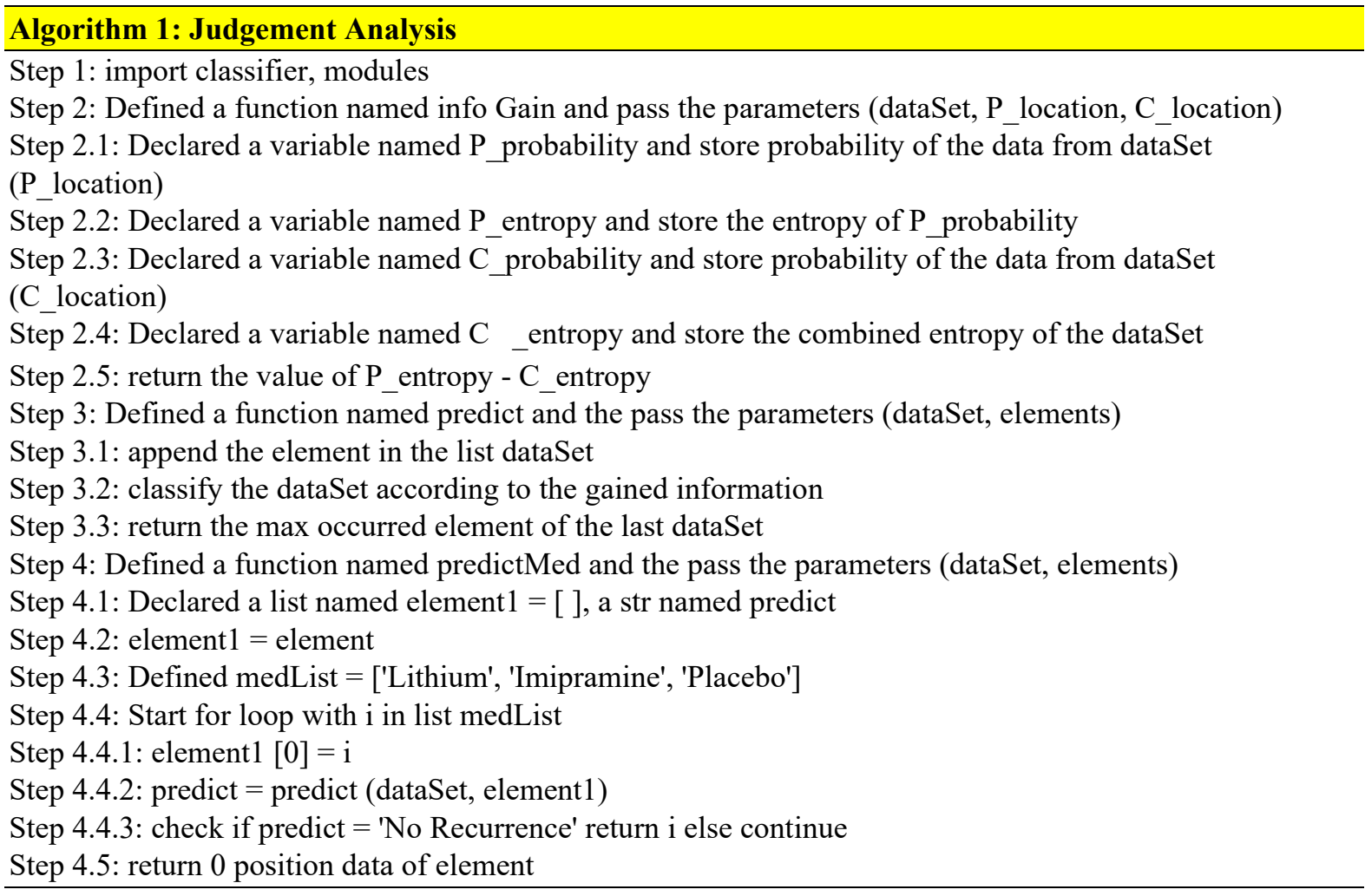




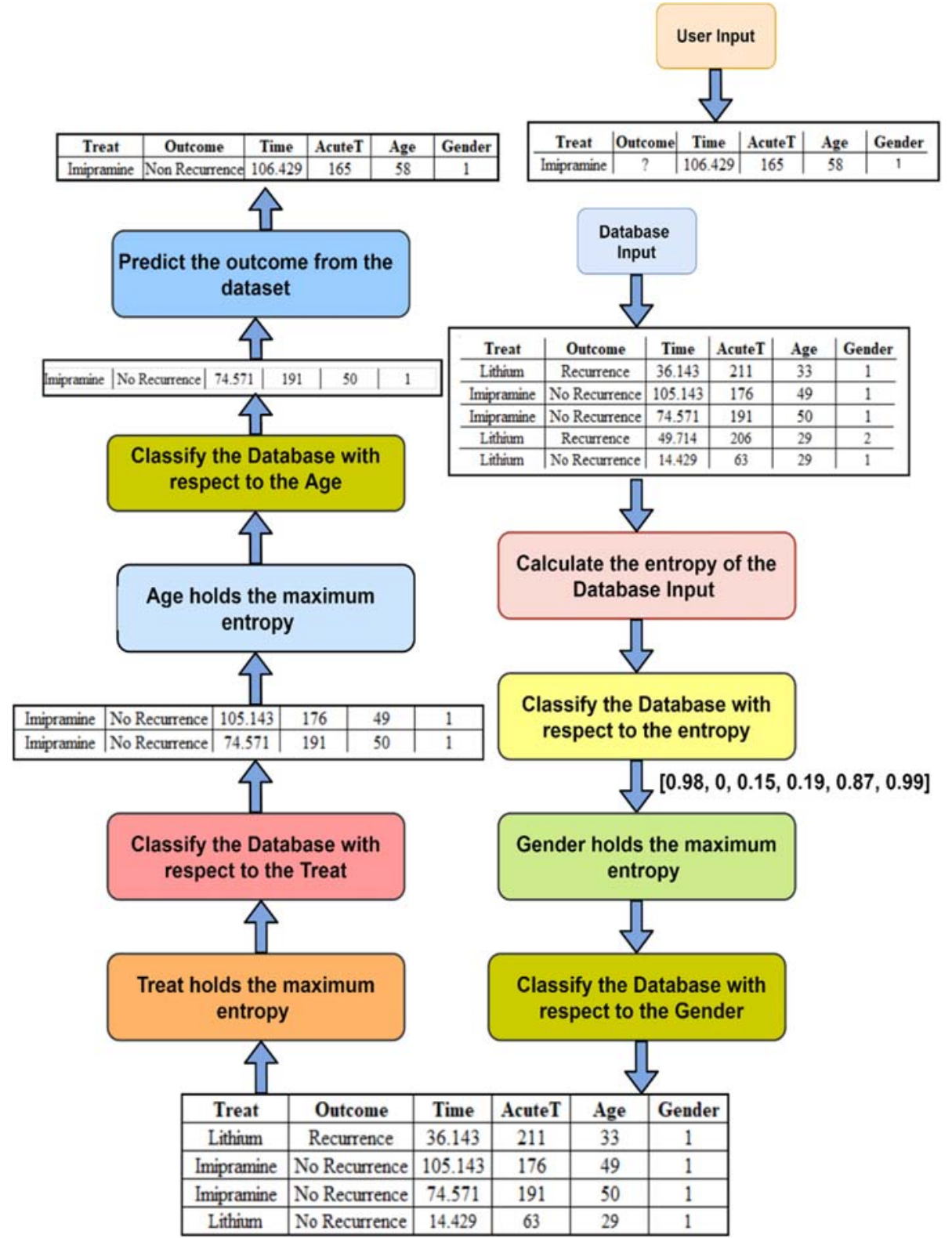

Fig. 1: Block diagram of Judgement Analysis algorithm for our proposed model

The suggested procedure of this research shows that it is categorized the dataset in regards with the breakage and "Sex" data that contains most of the breakages, what is illustrated in figure 1. Next, we categorize the dataset in regards with "Sex" and "Treat". This dataset contains most of the breakages. Then we categorize the dataset in regards with the "Treat" and "Age". They comprise in the most of the breakages. After that, we categorize the dataset in regards with the "Age". At this time, guess the result with the help of the dataset. In the algorithm which has suggested for making the diagram of this study in diagram 1, we have input from consumer. Besides, we are able to summon predict () function that fetches the result (Recurrence or Non Recurrence). Then get the utmost happenings you can have. After that if the utmost happenings you have, are "Non Recurrence" then get back the drugs that are akin to consumer input. On the contrary, get back the drugs in which the result gets "Non Recurrence" that is something different from the consumer input. Here Judgment Analysis (JA) Algorithm (Algorithm 1) has been implemented for the speculation of the drug on the basis of decision trees that is depicted in figure 1. 


\section{END-USERS WEB APPLICATION :}

This research [10] shows that the writers have applied significant information of the attributes and disadvantages of all machine learning algorithms that have been used for the prediction of mental attitude. For dejection, a great many machine learning methods recurrence and non-recurrence of choice and categorization were analyzed. For the configuration of replicas for having speculations of Machine Learning Algorithms were used. K-Nearest Neighbors (KNN), Support Vector Machine (SVM) and Random Forest were implemented in this study [10]. Three Confusion Matrix were uses to get the outcomes of the consummation, that for the capacity of the revelation of dejection. Among such algorithms these are the KNearest Neighbors which work most suitable, speculating $83 \%$ and the Random Forest by and by succeeds with 78\%. It is Confusion Matrix of K-Nearest Neighbors that has acquired the greatest precision [10]. Nevertheless, very small specimen sort has been confronted of this study.

For the development of the presentation the literature that subsists, the writers in this study [6], made a diagram of three decision trees. The first one is applied for the categorization with the application of gender, drug, and $<$ Time, AcuteT $>$. Likewise, the second one is used for the categorization with the implementation of gender, drug, and age. Equally, the third one is applied for the categorization with the implementation of age, drug, and $<$ Time, AcuteT $>$. On the basis of the output of such decision trees, the writers had different kinds of results from the group <Recurrence, No Recurrence>. When the feasible result shows "No Recurrence", the speculated drug becomes the identical drug which should be carried on by patient, or else, the speculated drug will be the drug in which the feasible result displays "No Recurrence" that is different from user input.

For the execution of suggested algorithms, in this research, the configured python-controlled web application end user that we have shown in diagram 2 and diagram 3 are constituted. Diagram 1 has represented a tabular representation of Mock-up trial events from the users. Besides it has conjectured the drug between Random Forest, K-Nearest Neighbor and Judgment Analysis Algorithm that also Table 2 [6] has illustrated. Table 3 has depicted the precision of this research's suggested Random Forest $\left(\mathrm{ACC}_{\mathrm{RF}}\right)$, K-Nearest Neighbor $\left(\mathrm{ACC}_{\mathrm{KNN}}\right)$, and Judgment Analysis $\left(\mathrm{ACC}_{\mathrm{JA}}\right)$ algorithms. It gives the evidence of the execution development of this subsisting literature.

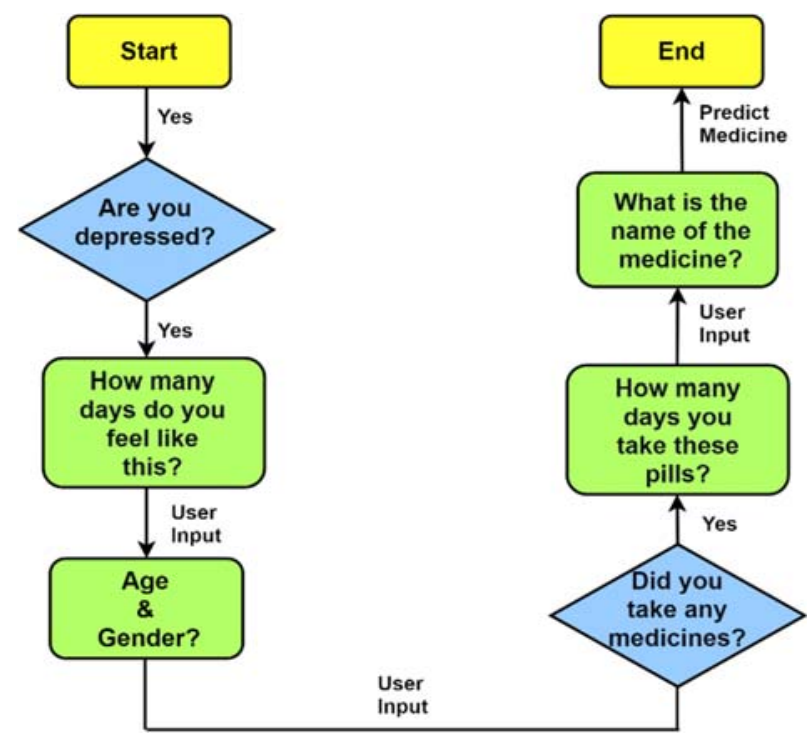

Fig. 2: Process flow diagram python-driven web application 
International Journal of Health Sciences and Pharmacy

(IJHSP), ISSN: 2581-6411, Vol. 5, No. 1, March 2021.

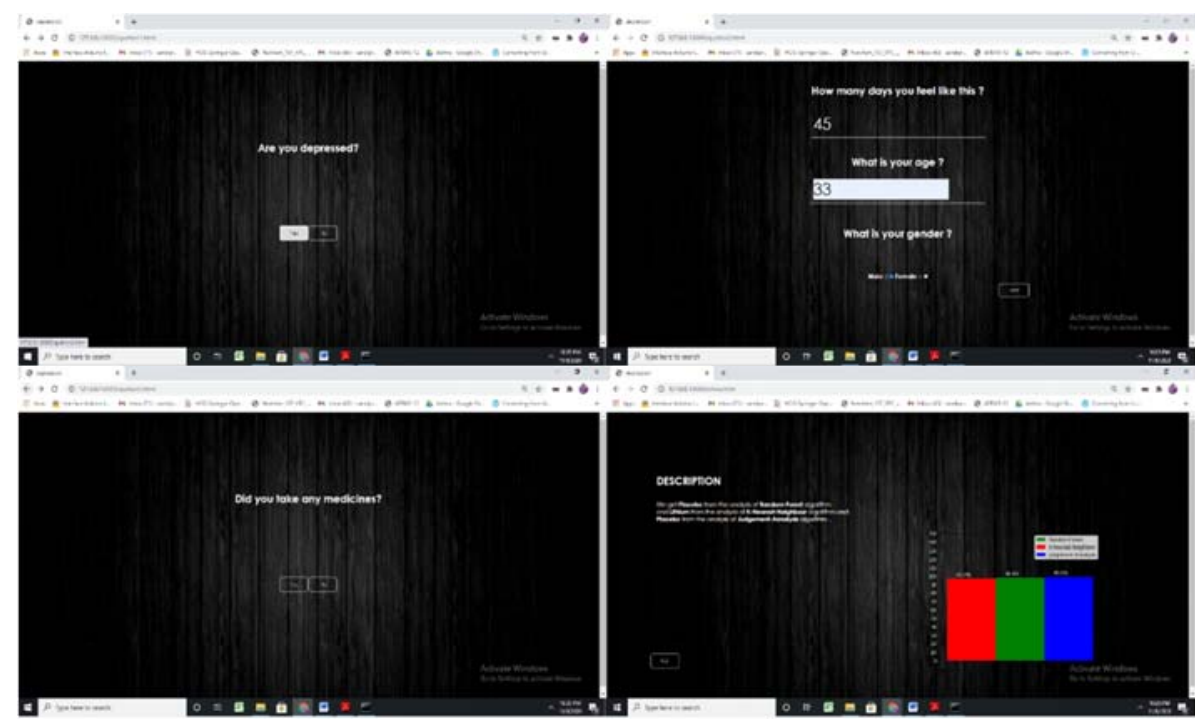

Fig. 3: Python-driven web application end-user interfaces

Table 1: User input dataset

\begin{tabular}{|c|c|c|c|c|}
\hline Time & Age & Gender & Acute T & Treat \\
\hline 45 & 33 & Male & 15 & Lithium \\
\hline 105 & 18 & Female & 20 & Imipramine \\
\hline 90 & 25 & Female & 30 & Imipramine \\
\hline 300 & 40 & Male & 60 & Lithium \\
\hline 50 & 25 & Female & 30 & Imipramine \\
\hline 150 & 47 & Female & 100 & Lithium \\
\hline 90 & 38 & Male & 50 & Imipramine \\
\hline 60 & 50 & Female & 30 & Lithium \\
\hline 365 & 55 & Male & 45 & Imipramine \\
\hline 200 & 70 & Female & 75 & Lithium \\
\hline
\end{tabular}

Table 2: Predicted Medicine between Random Forest, K-Nearest Neighbor and Judgement Analysis Algorithm

\begin{tabular}{|c|c|c|}
\hline Random Forest & $\begin{array}{c}\text { K-Nearest } \\
\text { Neighbor }\end{array}$ & Judgement Analysis \\
\hline Placebo & Lithium & Placebo \\
\hline Placebo & Imipramine & Placebo \\
\hline Lithium & Lithium & Placebo \\
\hline Imipramine & Imipramine & Lithium \\
\hline Lithium & Lithium & Imipramine \\
\hline Lithium & Placebo & Placebo \\
\hline Lithium & Imipramine & Lithium \\
\hline Lithium & Lithium & Placebo \\
\hline Imipramine & Imipramine & Lithium \\
\hline Imipramine & Imipramine & Placebo \\
\hline Lithium & Imipramine & Imipramine \\
\hline
\end{tabular}


Table 3: Accuracy between Random Forest, K-Nearest Neighbor and Judgement Analysis

\begin{tabular}{|c|c|c|}
\hline $\mathbf{A C C}_{\mathbf{R F}}$ & $\mathbf{A C C}_{\mathbf{K N N}}$ & $\mathbf{A C C}_{\mathbf{J A}}$ \\
\hline $90 \%$ & $97 \%$ & $98 \%$ \\
\hline $90 \%$ & $96 \%$ & $99 \%$ \\
\hline $93 \%$ & $96 \%$ & $97 \%$ \\
\hline $94 \%$ & $97 \%$ & $98 \%$ \\
\hline $94 \%$ & $96 \%$ & $99 \%$ \\
\hline $93 \%$ & $97 \%$ & $99 \%$ \\
\hline $93 \%$ & $97 \%$ & $99 \%$ \\
\hline $95 \%$ & $96 \%$ & $98 \%$ \\
\hline $95 \%$ & $96 \%$ & $97 \%$ \\
\hline $94 \%$ & $95 \%$ & $98 \%$ \\
\hline
\end{tabular}

\section{CONCLUSION :}

When we came to analysis procedure at the end, the outcomes of three different decision tree clarifiers are distinguished for discovering the link between expected result and the work of clarifiers with the suggested discernment evaluation algorithm. In this event, we noticed that the suggested discernment of the work of evaluation algorithm of this research was significant on the basis of the subsisting language. After that we manifested a composite procedure on the basis of suggested procedure. It also assumes the drug on the basis of the suggested discernment evaluation algorithm method of this research. Among such algorithms, the discernment evaluation algorithm worked first speculating roughly $98 \%$ aptly presently trailed by the knearest neighbor that has $96 \%$ and random forest that has $93 \%$. Nevertheless, the very small specimen and small features restrictions are confronted too by such study. Moreover, a probable restriction of this study states about the speculation of supplementary drug that may acquire supplementary attributes which obtain for dejection, when the exploratory results look favorable. In this research, a prospective guidance makes the inspection of the developments of explicit derivation as well as a preference policy.

\section{ACKNOWLEDGEMENT :}

The writers, who worked on this research, appreciatively concede to Computational Science Division of Srinivas University, Mukka, Mangalore, India, and Brainware University, West Bengal, as they gave those privileges to work in their laboratory as well as associated privileges to go on with their project.

\section{REFERENCES :}

[1] Facts \& Statistics, ADAA. https://adaa.org/about-adaa/press-room/facts-statistics. Accessed on $11 / 11 / 2020$.

[2] Berwian, I. M., Wenzel, J. G., Kuehn, L., Schnuerer, I., Seifritz, E., Stephan, K. E., Walter, H. \& Huys. Q. J. M. (2020). Low predictive power of clinical features for relapse prediction after antidepressant discontinuation in a naturalistic setting, Biological Psychiatry, 87(9), 1 - 24.

[3] Sagar, R. (2019). The burden of mental disorders across the states of India: the Global Burden of Disease Study 1990-2017, Lancet Psychiatry, 7(2), 148 - 161.

[4] Major Depression, https://www.nimh.nih.gov/health/statistics/major-depression.shtml. Accessed on $11 / 11 / 2020$.

[5] Depression, https://www.who.int/health-topics/depression\#tab=tab_1. Accessed on 11/11/2020.

[6] Roy, S., Aithal, P. S. \& Bose, R. (2020). A Novel Hybrid Approach for Diagnosis of Mental Health Condition Applying Intelligent Data Analysis, IJATCSE, 9(5), 7969 - 7979.

[7] Marcus, M., Yasamy, M. T., Ommeren, M. V. Chisholm, D. \& Saxena, S. (2020). DEPRESSION A Global Public Health Concern. Accessed on 11/11/2020. 
[8] Liu, Q., He, H., Yang, J. Feng, X., Zhao, F. \& Lyu, J. (2020). Changes in the global burden of depression from 1990 to 2017: findings from the Global Burden of Disease study, Journal of Psychiatric Research, 126(7), $134-140$.

[9] Friedrich, M. J. (2017). Depression Is the Leading Cause of Disability Around the World, JAMA, 315(15), 1517.

[10] Chandra, K., Bhattacharjee, P., Roy, S. \& Biswas, S. (2020). Intelligent Data Prognosis of Recurrent of Depression in Medical Diagnosis, in Proc. $20208^{\text {th }}$ Int. Conf. on Reliability, Infocom Technologies and Optimization (ICRITO), pp. 840 - 844.

[11] Nagata, T., Fujino, Y., Ohtani, M., Fujimoto, K., Nagata, M., Kajiki, S., Okawara, M. \& Mori, K. Work functioning impairment in the course of pharmacotherapy treatment for depression. Scientific Reports, 10(1512), 1 -8.

[12] Dunner, Dr. (2007). Preventing Recurrent Depression: Long-Term Treatment for Major Depressive Disorder. Primary Care Companion to The Journal of Clinical Psychiatry, 9(3), 214 - 223.

[13] Severe, J., Greden, J. F. \& Reddy. P. (2020). Consequences of Recurrence of Major Depressive Disorder: Is Stopping Effective Antidepressant Medications Ever Safe? Focus, 18(1), 120 - 128.

[14] Mocking, R. J. T, Figueroa, C. A., Rive, M. M, Geugies, H., Servaas, M. N., Assies, J., Koeter, M. W J, Vaz, F. M., Wichers, M., van Straalen, J. P., de Raedt, R., Bockting, C. L H., Harmer, C. J. Schene, A. H. \& Ruhé. H. G. (2016). Vulnerability for new episodes in recurrent major depressive disorder: protocol for the longitudinal DELTA-neuroimaging cohort study. BMJ Open, 6(3), $1-17$.

[15] Gotter, A. (2017). Recognizing Depression Relapse: How to Cope. healthline. https://www.healthline.com/health/depression-relapse. Accessed on 11/11/2020.

[16] Sim, K., Lau, W. K., Sim, J., Sum, M. Y. \& Baldessarini, R. J. (2016). Prevention of Relapse and Recurrence in Adults with Major Depressive Disorder: Systematic Review and Meta-Analyses of Controlled Trials. Int. J. of Neuropsychopharmacology, 19(2), 1 - 13.

[17] Depression: How effective are antidepressants? InformedHealth.org [Internet]. https://www.ncbi.nlm.nih.gov/books/NBK361016/\#: :text=In\%20other\%20words\%2C\%20antidepress ants\%20are,found\%20to\%20be\%20equally\%20effective. Accessed on 11/11/2020.

[18] Greenlaw, E. How Your Depression Medicine Can Affect Your Life. WebMD. https://www.webmd.com/depression/features/antidepressant-effects\#1. Accessed on 11/11/2020.

[19] Linden, M. \& Schermuly-Haupt, L. M. (2014). Definition, assessment and rate of psychotherapy side effects. World Psychiatry: official journal of the World Psychiatric Association (WPA), 13(3), 306-309.

[20] Locher, C., Meier, S. \& Gaab, J. (2019). Psychotherapy: A World of Meanings. Frontiers in psychology, Front Psychol., 10(460), $1-8$.

[21] Tartakovsky, M. (2018). Top Relapse Triggers for Depression \& How to Prevent Them. https://psychcentral.com/lib/top-relapse-triggers-for-depression-how-to-prevent-them\#1. Accessed on $11 / 11 / 2020$.

[22] Dey, S., Sarkar, I., Chakraborty, S., Roy, S. (2020). Depression Detection Using Intelligent Algorithms From Social Media Context - State of the Art, Trends and Future Roadmap, Journal of Xidian University, 14(8), 45 - 62.

[23] Lye, M-S., Tey, Y-Y., Tor, Y-S, Shahaboddin, A. F., Ibrahim, N., Ling, K-H., Stanslas, J., Loh, S-P., Rosli, R., Lokman, K. A., Badamasi, I. M., Faris-Aldoghachi, A. \& Razak, N. A. A. (2020). Predictors of recurrence of major depressive disorder, PLOS ONE, 15(3), 1- 15.

[24] Monroe, S. M. \& Harkness, K. L. (2011). Recurrence in major depression: A conceptual analysis, Psychol Rev, 118(4), 655-674.

[25] Vahia, V. N. (2013). Diagnostic and statistical manual of mental disorders 5: A quick glance, Indian J Psychiatry, 55(3), 220 - 223. 
[26] Kessler, R C. \& Bromet, E. J. (2013). The epidemiology of depression across cultures. Annu Rev Public Health, 34(7), 119-38.

[27] Lee, A. S. (2003). Better outcomes for depressive disorders? Psychol Med. 33(5), 769-774.

[28] Kessler, R. C. \& Wang, P.S. (2015). Handbook of Depression. In I. H. Gotlib \& C. L. Hammen, 3rd Ed. New York: Guilford Press, 3(11), 1 - 642.

[29] Roiser, J. P., Elliot, E. \& Sahakian, B. J. (2012). Cognitive Mechanisms of Treatment in Depression. Neuropsychopharmacology, 37(1), 117-136.

[30] Mueller, T. I., Leon, A. C., Keller, M. B., Solomon, D. A., Endicott, J. \& Coryell, W. (1999). Recurrence after recovery from major depressive disorder during 15 years of observational follow-up. Am $J$ Psychiatry. 156(7), $1000-1006$.

[31] Greden J. F. (2001). The burden of recurrent depression: causes, consequences, and future prospects. $J$ Clin Psychiatry, 62(22), 5 - 9.

[32] Nobile B., Lutz P. E., Olie E. \& Courtet P. (2020). The Role of Opiates in Social Pain and Suicidal Behavior. Curr Top Behav Neurosci, 46(1), 197-210.

[33] Cacheda, F., Fernandez, D., Novoa, F. J. \& Carneiro, V. (2019). Early Detection of Depression: Social Network Analysis and Random Forest Techniques. J Med Internet Res, 21(6), 1 - 18.

[34] Ramalingan, D., Sharma, V. \& Zar. P. (2019). Study of Depression Analysis using Machine Leatning Techniques, IJITEE, 8(7C2), $187-191$.

[35] Kroenke, K., Spitzer, R. \& Williams, J. B. (2001). The PHQ-9: validity of a brief depression severity measure. Journal of General Internal Medicine, 16(9), 606 - 613.

[36] Kroenke, K., Spitzer, R. L. \& Williams, J. B. (2003). The Patient Health Questionnaire-2: validity of a two-item depression screener. Medical Care, 41(11), 1284-92.

[37] Pratap, A., Renn, B. N., Volponi, J., Mooney, S. D., Gazzaley, A., Arean, P. A. \& Anguera, J. A. (2018). Using Mobile Apps to Assess and Treat Depression in Hispanic and Latino Populations: Fully Remote Randomized Clinical Trial. J Med Internet Res. 20 (8), e10130.

[38] Bidargaddi, N., Musiat, P., Winsall, M., Vogl, G., Blake, V., Quinn, S., Orlowski, S., Antezana, G. \& Schrader, G. (2017). Efficacy of a Web-Based Guided Recommendation Service for a Curated List of Readily Available Mental Health and Well-Being Mobile Apps for Young People: Randomized Controlled Trial. J Med Internet Res., 19(5), e141.

[39] Weisel, K. K., Fuhrmann, L. M., Berking, M., Baumeister, H., Cuijpers, P. \& Ebert, D. D. (2019). Standalone smartphone apps for mental health - a systematic review and meta-analysis. NPJ Digit. Med., 2(118), 1 -10.

[40] Chisholm, D. Sweeny, K., Sheehan, P. Rasmussen, B., Smit, F., Cuijpers, P. \& Saxena, S. Scaling-up treatment of depression and anxiety: a global return on investment analysis. The Lancet Psychiatry, 3(5), $415-424$.

[41] Richards, D., Richardson, T., Timulak, L. \& McElvaney, J. (2015). The efficacy of internet-delivered treatment for generalized anxiety disorder: a systematic review and meta-analysis. Internet Interv. 2(3), $272-282$.

[42] Barth, J., Munder, T., Gerger, H., Nüesch, E., Trelle, S., Znoj, H., Jüni, P. \& Cuijpers, P. (2016). Comparative efficacy of seven psychotherapeutic interventions for patients with depression: a network meta-analysis. Focus, 10(5), 229-243.

[43] Whittaker R., Stasiak, K., McDowell, H., Doherty, I., Shepherd, M., Chua, S., Dorey, E., Parag, V., Ameratunga, S., Rodgers, A., Merry, S. (2017). MEMO: an mHealth intervention to prevent the onset of depression in adolescents: a double-blind, randomised, placebo-controlled trial. Journal of Child Psychology Psychiatry, 58(9), 1014-1022. 
[44] Bauer, M., Glenn, T., Geddes, J., Gitlin, M., Grof, P., Kessing, L. V., Monteith, S., Faurholt-Jepsen, M., Severus, E., Whybrow, P. C. (2020). Smartphones in mental health: a critical review of background issues, current status and future concerns, International Journal of Bipolar Disorders, 8(2), 1-19.

[45] Michelle, M. Ng., Firth, J., Minen, M. \& Torous, J. (2019). User Engagement in Mental Health Apps: A Review of Measurement, Reporting, and Validity. Psychiatric Services, 70(7), 538-544, 2019.

[46] O'Loughlin, K. Neary, M., Adkins, E. C. \& Schueller, S. M. (2019). Reviewing the data security and privacy policies of mobile apps for depression, Internet Interventions, 15(3), 110-115.

[47] Sharma, A. \& Verbeke, W. J. M. I. (2020). Improving Diagnosis of Depression with XGBOOST Machine Learning Model and a Large Biomarkers Dutch Dataset $(\mathrm{n}=11,081)$. Frontiers in Big Data, 3(4), 1-11.

[48] Nguyen, M.-H., Ho, M.T., Nguye, Q.-Y. T. \& Vuong, Q.-H. (2019). A Dataset of Students' Mental Health and Help-Seeking Behaviors in a Multicultural Environment. Data, 4(3), 1-16.

[49] Lu, H.P., Yang, Y.-W. \& Chen, W.-H. (2011). The Analysis of Human Judgment Accuracy Using Decision Tree Models, International Conference on Uncertainty Reasoning and Knowledge Engineering, 90 - 93.

[50] Das, S. \& Cakmak, U. M. (2018). Hands-On Automated Machine Learning: A beginner's guide to building automated machine learning systems using AutoML and Python. Packt Publishing, 1 - 282. 